Research Paper

\title{
Relationship between Stroke Volume Variation and Blood Transfusion during Liver Transplantation
}

\author{
Jae Moon Choi ${ }^{1}$, Yoon Kyung Lee ${ }^{2}$, Hwanhee Yoo $^{1}$, Sukyung Lee ${ }^{1}$, Hee Yeong Kim², ${ }^{\circledR}$, and Young-Kug \\ $\mathrm{Kim}^{1}{ }^{凶}$
}

1. Department of Anesthesiology and Pain Medicine, Asan Medical Center, University of Ulsan College of Medicine, Seoul, Republic of Korea.

2. Department of Anesthesiology and Pain Medicine, Hangang Sacred Heart Hospital, Hallym University College of Medicine, Seoul, Republic of Korea.

$\triangle$ Corresponding authors: Young-Kug Kim, MD, PhD, Professor, Department of Anesthesiology and Pain Medicine, Asan Medical Center, University of Ulsan College of Medicine, Seoul 05505, Republic of Korea. Phone: +82-2-3010-5976, Fax: +82-2-3010-6790, E-mail: kyk@amc.seoul.kr; and Hee Yeong Kim, MD, Clinical Assistant Professor, Department of Anesthesiology and Pain Medicine, Hangang Sacred Heart Hospital, Hallym University College of Medicine, Seoul 07247, Republic of Korea. Phone: +82-2-2639-5500, Fax: +82-2-2633-7571, E-mail: kamangkebi@naver.com.

() Ivyspring International Publisher. Reproduction is permitted for personal, noncommercial use, provided that the article is in whole, unmodified, and properly cited. See http://ivyspring.com/terms for terms and conditions.

Received: 2015.10.21; Accepted: 2016.02.04; Published: 2016.02.20

\begin{abstract}
Background. Intraoperative blood transfusion increases the risk for perioperative mortality and morbidity in liver transplant recipients. A high stroke volume variation (SVV) method has been proposed to reduce blood loss during living donor hepatectomy. Herein, we investigated whether maintaining high SVV could reduce the need for blood transfusion and also evaluated the effect of the high SVV method on postoperative outcomes in liver transplant recipients.

Methods. We retrospectively analyzed 332 patients who underwent liver transplantation, divided into control (maintaining $<10 \%$ of SVV during surgery) and high SVV (maintaining $10-20 \%$ of SVV during surgery) groups. We evaluated the blood transfusion requirement and hemodynamic parameters, including SVV, as well as postoperative outcomes, such as incidences of acute kidney injury, durations of postoperative intensive care unit and hospital stay, and rates of 1-year mortality.

Results. Mean SVV values were $7.0 \% \pm 1.3 \%$ in the control group $(n=288)$ and $11.2 \% \pm 1.8 \%$ in the high SVV group $(n=44)$. The median numbers of transfused packed red blood cells and fresh frozen plasmas in the high SVV group were significantly lower than those in control group ( 0 vs. 2 units, $P=0.003$; and 0 vs. 3 units, $P=0.033$, respectively). No significant between-group differences were observed for postoperative outcomes.

Conclusions. Maintaining high SVV can reduce the blood transfusion requirement during liver transplantation without worsening postoperative outcomes. These findings provide insights into improving perioperative management in liver transplant recipients.
\end{abstract}

Key words: stroke volume variation; liver transplantation; blood transfusion.

\section{Introduction}

Liver transplantation is associated with massive blood loss and blood transfusion that are mainly consequences of the complex surgical procedures and derangements of the coagulation system. Importantly, intraoperative blood loss and subsequent blood transfusion increases the risk for perioperative mortality and morbidity in liver transplant recipients.[1-4] Therefore, minimizing the need for intraoperative blood transfusion represents a key objective for maximizing perioperative outcomes in these patients. Several strategies have been proposed to reduce intraoperative blood loss and blood transfusion. Several randomized clinical trials have found that restrictive transfusion strategy yields equivalent or superior outcomes compared with a liberal strategy.[5-7] The low central venous pressure technique has been found to reduce intraoperative blood loss and red blood cell (RBC) transfusion during liver 
transplantation. $[8,9]$ Recently, our group found that blood loss during living donor hepatectomy was significantly lower in donors who maintained $10-20 \%$ of stroke volume variation (SVV) compared with those who maintained $<10 \%$ of SVV.[10, 11] However, no study has yet reported the relationship between the high SVV method (i.e. maintaining $10-20 \%$ of SVV during surgery) and intraoperative blood transfusion in liver transplant recipients, who are frequently at risk for blood transfusion during liver transplantation.

Herein, we investigated whether maintaining high SVV could reduce the requirement for blood transfusion during liver transplantation. Additionally, we evaluated the effects of the high SVV method on postoperative outcomes in liver transplant recipients.

\section{Materials and Methods}

After obtaining institutional review board approval, the electronic medical records for patients aged $\geq 18$ years who underwent liver transplantation at Asan Medical Center between December 2009 and December 2013 were retrospectively reviewed. Patients who received more than 5 units of packed RBCs for transfusions during surgical procedures were excluded. Additional exclusion criteria included a history of previous liver transplantation, cardiac arrhythmia, and the intraoperative use of inotropics or a cell-saver.

Liver transplantation procedures were performed by a dedicated team using the standard anesthesia protocol of Asan Medical Center.[12-14] After applying routine hemodynamic monitoring, general anesthesia was induced with thiopental, fentanyl, and vecuronium. Following endotracheal intubation, anesthesia was maintained using sevoflurane, a 50\% $\mathrm{O}_{2}$ /air mixture, vecuronium, and fentanyl. Mechanical ventilation was performed using a constant tidal volume of $8-10 \mathrm{~mL} / \mathrm{kg}$ and a respiratory rate of $10-12$ cycles/min to maintain a constant end-tidal $\mathrm{CO}_{2}$ partial pressure of 30-35 $\mathrm{mmHg}$. Positive end-expiratory pressure was not administered. Fluids, including Plasmalyte, normal saline, half normal saline, and 5\% albumin, were administered during surgery. If intraoperative hematocrit and prothrombin time were $<25 \%$ and $>2.0$ international normalization ratio, packed RBCs or fresh frozen plasmas (FFPs) were transfused, respectively.

The following variables were recorded: demographic data, Child-Pugh score, model for end-stage liver disease score, laboratory test results, preoperative co-morbidities, and primary liver disease. We also recorded the requirement for blood transfusion with packed RBCs and/or FFPs, anesthesia time, volume of infused fluids, volume of urine output, incidences of acute kidney injury according to the Acute Kidney Injury Network criteria,[15] lengths of postoperative intensive care unit and hospital stay, and 1-year mortality rates.

The FloTrac sensor and Vigileo monitor (Edwards Lifesciences, Irvine, CA) were used to analyze arterial pressure waveform data over 20-sec intervals, using a recalibration interval of $1 \mathrm{~min}$. A Swan-Ganz CCOmbo pulmonary artery catheter (Edwards Lifesciences) was inserted via an introducer sheath into the internal jugular vein and advanced to a wedged position under guidance of the pressure curve. The pulmonary artery catheter was connected to a Vigilance II monitor (Edwards Lifesciences), and the STAT-mode right ventricular end-diastolic volume index was measured over 1-min intervals. A multi-data logger (Edwards Lifesciences) was used to simultaneously capture and store patient data from the Vigilance II monitor and Vigileo devices. We obtained hemodynamic parameters, including invasive arterial pressure, central venous pressure, pulmonary artery pressure, SVV, and the right ventricular end-diastolic volume index from each patient at six time points as follows: 1 and $2 \mathrm{~h}$ after skin incision, 30 min before and after extraction of the diseased liver, $30 \mathrm{~min}$ after reperfusion of the transplanted liver, and at the completion of hepatic artery reconstruction. Values for hemodynamic parameters measured at six specific time points were obtained by determining the means of measurements taken over 3-min intervals. Mean measurements of each hemodynamic parameter were used for statistical analysis.

Continuous data were tested for normal distribution using the Shapiro-Wilk test. Data are presented as means \pm SD for normally distributed continuous variables, medians (interquartile range) for skewed data, and numbers (\%) for categorical variables. Liver transplant recipients were divided into two groups: control (who maintained $<10 \%$ of SVV during surgery) and high SVV groups (who maintained $10-20 \%$ of SVV during surgery). Continuous variables were compared using Student's $t$-test or the Mann-Whitney U test, as appropriate. Categorical data were compared using the $\chi^{2}$ test or Fisher's exact test to assess differences between the two groups, as appropriate. A $P$-value of $<0.05$ was used as a threshold for statistically significant differences. Statistical analyses were performed using SPSS version 21.0 (IBM Corp., Armonk, NY).

\section{Results}

A total of 1480 liver transplantation were performed between December 2009 and December 2013 at our hospital. Among these procedures, 1148 cases 
were excluded, from our current analyses, including 65 cases with a history of previous liver transplantation, 448 with intraoperative use of inotropics, 607 with blood transfusion with more than 5 units of packed RBCs, 23 with cardiac arrhythmias, and 5 with incomplete medical records. Ultimately, 332 liver transplant recipients were therefore included in our present study. The number of recipients in the high SVV group was 44 (13.3\%).

Table 1 presents preoperative characteristics for our study patients. The mean age of the subjects in our current series was 52.1 years and $79.5 \%$ of these recipients were male. The mean preoperative hematocrit and platelet levels were $36.8 \%$ and $92.1 \times 10^{9} / \mathrm{L}$, respectively. No significant differences in preoperative variables were detected between groups.

Intraoperative variables and postoperative outcomes are listed in Table 2. The mean SVV was 7.0\% in the control group and $11.2 \%$ in the high SVV group, respectively. The mean central venous pressure and right ventricular end-diastolic volume index values were significantly lower in the high SVV group than in the control group. The median number of packed RBCs that were transfused in the high SVV group was significantly lower than those in the control group (0 vs. 2 units, $P=0.003$ ). The median number of transfused FFPs was also significantly lower in the high SVV group than in the control group ( 0 vs. 3 units, $P=$ 0.033 ). Figure 1 shows the number of packed RBCs and FFPs transfused in control and high SVV groups.

Table 2. Intraoperative variables and postoperative outcomes.

\begin{tabular}{|c|c|c|c|}
\hline Variables & $\begin{array}{l}\text { Control group } \\
(\mathrm{n}=288)\end{array}$ & $\begin{array}{l}\text { High SVV group } \\
\qquad(\mathrm{n}=44)\end{array}$ & $P$-value \\
\hline \multicolumn{4}{|l|}{ Intraoperative variables } \\
\hline SVV (\%) & $7.0 \pm 1.3$ & $11.2 \pm 1.8$ & $<0.001$ \\
\hline $\begin{array}{l}\text { Central venous pressure } \\
(\mathrm{mmHg})\end{array}$ & $6.6 \pm 1.3$ & $5.8 \pm 1.5$ & $<0.001$ \\
\hline $\operatorname{RVEDVI}\left(\mathrm{mL} / \mathrm{m}^{2}\right)$ & $148.9 \pm 22.3$ & $132.5 \pm 20.7$ & $<0.001$ \\
\hline $\begin{array}{l}\text { Packed RBCs transfused } \\
\text { (units) }\end{array}$ & $2(0-4)$ & $0(0-2)$ & 0.003 \\
\hline FFPs transfused (units) & $3(0-6)$ & $0(0-4)$ & 0.033 \\
\hline $\begin{array}{l}\text { Fluid infused } \\
(\mathrm{mL} / \mathrm{kg} / \mathrm{h})\end{array}$ & $10.0 \pm 3.1$ & $8.7 \pm 2.3$ & 0.007 \\
\hline Urine output (mL) & $1869 \pm 1090$ & $1580 \pm 723$ & 0.025 \\
\hline Surgical time (min) & $755 \pm 100$ & $785 \pm 103$ & 0.066 \\
\hline \multicolumn{4}{|l|}{ Postoperative outcomes } \\
\hline Hematocrit (\%) & $31.6 \pm 4.6$ & $31.1 \pm 4.8$ & 0.463 \\
\hline Acute kidney injury & $64(22.2)$ & $9(20.5)$ & 1.000 \\
\hline $\begin{array}{l}\text { Intensive care unit stay } \\
\text { (days) }\end{array}$ & $1(1-3)$ & $1(1-2)$ & 0.276 \\
\hline Hospital stay (days) & $22(20-28)$ & $20(18-25)$ & 0.067 \\
\hline 1-year mortality & $12(4.2)$ & $1(2.3)$ & 1.000 \\
\hline
\end{tabular}
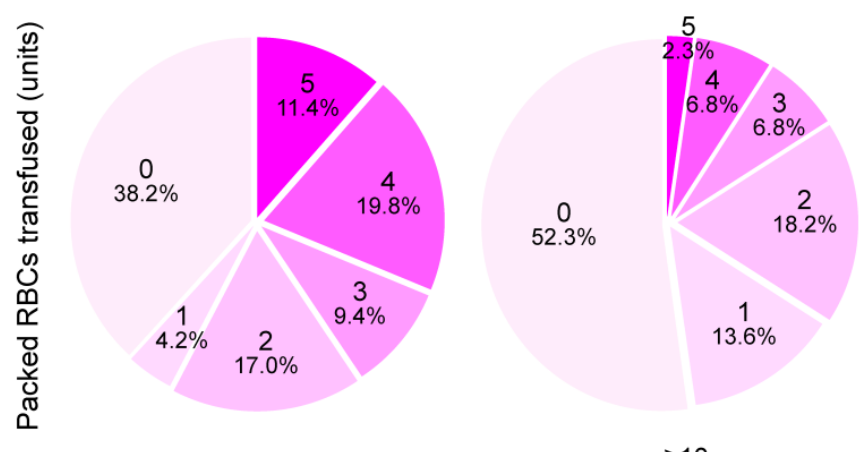

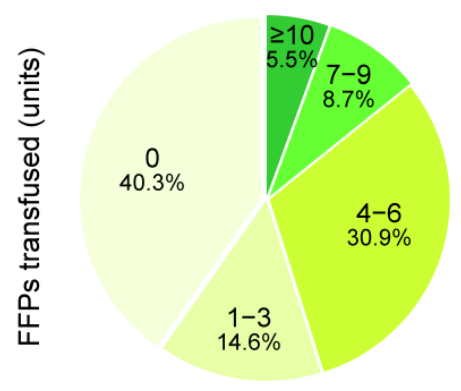

Control group

\begin{tabular}{llll}
\hline Variables & $\begin{array}{l}\text { Control group } \\
(\mathrm{n}=288)\end{array}$ & $\begin{array}{l}\text { High SVV group } \\
(\mathrm{n}=44)\end{array}$ & $P$-value \\
\hline Gender (male) & $229(79.5)$ & $35(79.5)$ & 1.000 \\
Age (years) & $51.7 \pm 8.3$ & $54.3 \pm 6.0$ & 0.053 \\
Body weight $(\mathrm{kg})$ & $69.9 \pm 10.0$ & $69.7 \pm 11.4$ & 0.904 \\
Height $(\mathrm{cm})$ & $167.5 \pm 7.4$ & $166.1 \pm 7.9$ & 0.242 \\
Child-Pugh score & $6(5-7)$ & $6(5-7)$ & 0.318 \\
MELD score & $9(7-12)$ & $8(7-12)$ & 0.548 \\
Hematocrit $(\%)$ & $36.7 \pm 5.7$ & $37.4 \pm 4.7$ & 0.396 \\
Platelet count $\left(10^{9} / \mathrm{L}\right)$ & $90.1 \pm 55.1$ & $105.5 \pm 54.5$ & 0.083 \\
Prothrombin time (INR) & $1.31 \pm 0.52$ & $1.38 \pm 0.91$ & 0.590 \\
Serum creatinine (mg/dL) & $0.76 \pm 0.19$ & $0.81 \pm 0.20$ & 0.091 \\
Primary liver disease & & & 0.159 \\
$\quad$ Cirrhosis with HCC & $206(71.5)$ & $38(86.4)$ & \\
$\quad$ Hepatitis & $68(23.6)$ & $5(11.4)$ & \\
$\quad$ Alcoholic cirrhosis & $9(3.1)$ & $0(0.0)$ & \\
$\quad$ Biliary cirrhosis & $5(1.7)$ & $1(2.3)$ & \\
Type of donor & & & \\
$\quad$ Single & $276(95.8)$ & $41(93.2)$ & \\
$\quad$ Dual & $6(2.1)$ & $3(6.8)$ & \\
Cadaveric & $6(2.1)$ & $0(0.0)$ & \\
\hline
\end{tabular}

Values are expressed as means $\pm \mathrm{SD}$, medians (interquartile range), or numbers (\%). MELD, model for end-stage liver disease; INR, international normalization ratio; HCC, hepatocarcinoma.

The average infused volume of fluid was 10.0 and 8.7 $\mathrm{mL} / \mathrm{kg} / \mathrm{h}$ in control and high SVV groups, respectively. No significant between-group differences were observed for the incidence of acute kidney injury, the duration of postoperative intensive care unit and hospital stay, and the 1-year mortality rate in liver transplant recipients.

Table 1. Preoperative variables. 


\section{Discussion}

In this present study, we found that the transfusion requirements for packed RBC and FFP were significantly lower in the high SVV group (who maintained $10-20 \%$ of SVV) than in the control group (who maintained $<10 \%$ of SVV) during liver transplantation. Additionally, there were no significant between-group differences in postoperative outcomes among liver transplant recipients.

Liver transplant recipients are known to be at risk of massive blood loss and coagulopathy, which is associated with the requirement for the considerable transfusion of blood and blood products. Although many causes have been attributed to hemorrhage, the technical difficulties inherent to the complex surgical procedure required for organ transplantation and coagulation abnormalities associated with end-stage liver disease appear to be main causes of perioperative hemorrhage in liver transplant recipients. With greater experience in the advanced surgical techniques that are required along with meticulous anesthetic management for liver transplantation, the intraoperative requirements for blood transfusion have decreased and blood transfusion-free transplantations now occur more frequently.[16] Several centers have reported that up to $40 \%$ of liver transplant recipients now no longer involve the transfusion of RBCs.[2, 17] Despite these accomplishments, intraoperative blood transfusion is still frequently required in liver transplant recipients.

Several studies have reported an association between blood transfusion and poorer postoperative outcomes.[18-20] The deleterious influences of allogeneic blood transfusion extend beyond the well-known sequela of viral transmission and include transfusion-related acute lung injury, graft-versus-host disease, renal failure, postoperative infection, and tumor recurrence.[21] Additionally, several studies have shown that intraoperative blood transfusion has a negative impact on the outcomes of liver transplantation.[1-4] One of best ways to prevent a worsening of postoperative outcomes is to diminish the need for blood transfusion in liver transplant recipients.

In our present study, we found that maintaining a high SVV can contribute to reduced blood transfusion requirements in liver transplant recipients. The utility of SVV in guiding intraoperative fluid administration has been reported in many clinical contexts, such as in hepatic and neurosurgical surgeries.[10, 22, 23] Importantly, our group has previously suggested that maintaining a high SVV is a useful way to reduce blood loss during living donor right hepatectomy.[10, 11, 24] Additionally, a higher SVV value has been reported to correlate with a lower right ventricular end-diastolic volume index value in liver transplant recipients.[12] The maintenance of a high SVV appears to induce lower normal levels of intravascular volume and to thereby prevent vascular congestion. Furthermore, the restricted administration of fluid may avoid a reduction in platelet numbers and the dilution of coagulation factors.[9]

We also found in our present analyses that the high SVV method did not exert detrimental effects on renal function. Our findings are in accord with those of Feng et al., who reported that the low central venous pressure technique had no harmful effects on perioperative renal function or postoperative outcomes.[8]

We excluded patients with massive blood loss, who were defined as having received more than five units of packed RBCs during liver transplantation. This criterion is comparable with previously reported definition in cardiac surgery.[25] Maintaining an adequate volume status may be difficult in patients who undergo a large volume blood transfusion. Moreover, perioperative bleeding can be exacerbated by the administration of blood products, most likely because of hypothermia, hypocalcemia, and dilution of the coagulation factors.

Our present analysis had several possible limitations. Because of our retrospective study design, careful interpretation is required to evaluate the potential association between the high SVV method and blood transfusion. However, all procedures were performed by the same surgical team at our hospital and no statistical differences between groups were detected when the preoperative and postoperative levels of hematocrit were compared. Furthermore, the number of transfused packed RBCs and SVV, which were the primary variables of interest, represented objective variables that were collected in a blind manner. Another possible limitation was use of the number of packed RBCs that were transfused during the surgical procedure as a surrogate measure of intraoperative blood loss. Clinical estimates of intraoperative blood loss are notoriously difficult to accurately evaluate,[26] while a simple way to assess this parameter is to quantify the requirement for blood transfusions.

In conclusion, we find from our present analysis that maintaining a high SVV is an effective method for reducing the blood transfusion requirements during liver transplantation without worsening the postoperative outcomes. This offers useful insights into the value of SVV measurements, as they highlight the possibility of avoiding unnecessary and potentially harmful blood transfusion in liver transplant recipients. 


\section{Competing Interests}

\section{The authors declare no conflicts of interest.}

\section{References}

1. de Boer MT, Christensen MC, Asmussen M, van der Hilst CS, Hendriks HG, Slooff MJ, et al. The impact of intraoperative transfusion of platelets and red blood cells on survival after liver transplantation. Anesth Analg. 2008; 106: $32-44$.

2. Ramos E, Dalmau A, Sabate A, Lama C, Llado L, Figueras J, et al. Intraoperative red blood cell transfusion in liver transplantation: influence on patient outcome, prediction of requirements, and measures to reduce them. Liver Transpl. 2003; 9: 1320-7.

3. Massicotte L, Beaulieu D, Thibeault L, Roy JD, Marleau D, Lapointe R, et al. Coagulation defects do not predict blood product requirements during liver transplantation. Transplantation. 2008; 85: 956-62.

4. Chung HS, Jung DH, Park CS. Intraoperative predictors of short-term mortality in living donor liver transplantation due to acute liver failure. Transplant Proc. 2013; 45: 236-40.

5. Hajjar LA, Vincent JL, Galas FR, Nakamura RE, Silva CM, Santos MH, et al. Transfusion requirements after cardiac surgery: the TRACS randomized controlled trial. JAMA. 2010; 304: 1559-67.

6. Villanueva C, Colomo A, Bosch A, Concepcion M, Hernandez-Gea V, Aracil C, et al. Transfusion strategies for acute upper gastrointestinal bleeding. N Engl J Med. 2013; 368: 11-21.

7. Carson JL, Terrin ML, Noveck H, Sanders DW, Chaitman BR, Rhoads GG, et al. Liberal or restrictive transfusion in high-risk patients after hip surgery. $\mathrm{N}$ Engl J Med. 2011; 365: 2453-62.

8. Feng $\mathrm{ZY}, \mathrm{Xu} \mathrm{X}$, Zhu SM, Bein B, Zheng SS. Effects of low central venous pressure during preanhepatic phase on blood loss and liver and renal function in liver transplantation. World J Surg. 2010; 34: 1864-73.

9. Massicotte L, Lenis S, Thibeault L, Sassine MP, Seal RF, Roy A. Effect of low central venous pressure and phlebotomy on blood product transfusion requirements during liver transplantations. Liver Transpl. 2006; 12: 117-23.

10. Choi SS, Jun IG, Cho SS, Kim SK, Hwang GS, Kim YK. Effect of stroke volume variation-directed fluid management on blood loss during living-donor right hepatectomy: a randomised controlled study. Anaesthesia. 2015; 70: 1250-8.

11. Seo H, Jun IG, Ha TY, Hwang S, Lee SG, Kim YK. High Stroke Volume Variation Method by Mannitol Administration Can Decrease Blood Loss During Donor Hepatectomy. Medicine (Baltimore). 2016; 95: e2328.

12. Kim SH, Hwang GS, Kim SO, Kim YK. Is stroke volume variation a useful preload index in liver transplant recipients? A retrospective analysis. Int J Med Sci. 2013; 10: 751-7.

13. Kong YG, Kang JW, Kim YK, Seo H, Lim TH, Hwang S, et al. Preoperative coronary calcium score is predictive of early postoperative cardiovascular complications in liver transplant recipients. Br J Anaesth. 2015; 114: 437-43.

14. Kong YG, Ha TY, Kang JW, Hwang S, Lee SG, Kim YK. Incidence and Predictors of Increased Coronary Calcium Scores in Liver Transplant Recipients. Transplant Proc. 2015; 47: 1933-8.

15. Mehta RL, Kellum JA, Shah SV, Molitoris BA, Ronco C, Warnock DG, et al. Acute Kidney Injury Network: report of an initiative to improve outcomes in acute kidney injury. Crit Care. 2007; 11: R31.

16. Clevenger B, Mallett SV. Transfusion and coagulation management in liver transplantation. World J Gastroenterol. 2014; 20: 6146-58.

17. Massicotte L, Sassine MP, Lenis S, Seal RF, Roy A. Survival rate changes with transfusion of blood products during liver transplantation. Can J Anaesth. 2005; 52: 148-55.

18. Ejaz A, Spolverato G, Kim Y, Frank SM, Pawlik TM. Variation in triggers and use of perioperative blood transfusion in major gastrointestinal surgery. Br J Surg. 2014; 101: 1424-33.

19. Bernard AC, Davenport DL, Chang PK, Vaughan TB, Zwischenberger JB. Intraoperative transfusion of $1 \mathrm{U}$ to $2 \mathrm{U}$ packed red blood cells is associated with increased 30-day mortality, surgical-site infection, pneumonia, and sepsis in general surgery patients. J Am Coll Surg. 2009; 208: 931-7.

20. Ferraris VA, Davenport DL, Saha SP, Austin PC, Zwischenberger JB. Surgical outcomes and transfusion of minimal amounts of blood in the operating room. Arch Surg. 2012; 147: 49-55.

21. Raghavan M, Marik PE. Anemia, allogenic blood transfusion, and immunomodulation in the critically ill. Chest. 2005; 127: 295-307.

22. Zhang Z, Lu B, Sheng X, Jin N. Accuracy of stroke volume variation in predicting fluid responsiveness: a systematic review and meta-analysis. J Anesth. 2011; 25: 904-16.

23. Dunki-Jacobs EM, Philips P, Scoggins CR, McMasters KM, Martin RC, 2nd. Stroke volume variation in hepatic resection: a replacement for standard central venous pressure monitoring. Ann Surg Oncol. 2014; 21: 473-8.

24. Choi SS, Kim SH, Kim YK. Fluid management in living donor hepatectomy: Recent issues and perspectives. World J Gastroenterol. 2015; 21: 12757-66.

25. Karkouti K, Wijeysundera DN, Yau TM, Beattie WS, Abdelnaem E, McCluskey $\mathrm{SA}$, et al. The independent association of massive blood loss with mortality in cardiac surgery. Transfusion. 2004; 44: 1453-62.

26. Brecher ME, Monk T, Goodnough LT. A standardized method for calculating blood loss. Transfusion. 1997; 37: 1070-4 